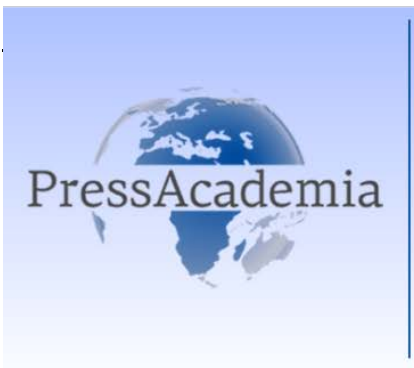

Press Academia Procedía

Global Business Research Congress (GBRC), May 26-27, 2016, Istanbul, Turkey.

\title{
A FIELD WORK TO DETERMINE INTENTIONS OF STAYING IN ACCOUNTING SECTOR AND THE HOPELESSNESS LEVEL OF THE STUDENTS HAVING ACCOUNTING EDUCATION
}

DOI: 10.17261/Pressacademia.2016118641

\author{
Furkan Yildirim ${ }^{1}$, Aysegul Ciger ${ }^{2}$, Ahmet Kaya ${ }^{3}$, Filiz Angay Kutluk ${ }^{4 *}$ \\ ${ }^{1}$ Akdeniz Üniversitesi, furkanyildirim@akdeniz.edu.tr \\ ${ }^{2}$ Akdeniz Üniversitesi, aysegulc@akdeniz.edu.tr \\ ${ }^{3}$ Akdeniz Üniversitesi, ahmetkaya@akdeniz.edu.tr \\ ${ }^{4}$ Akdeniz Üniversitesi, angay@akdeniz.edu.tr
}

\begin{abstract}
Hopelessness concept is the status of the people that losing their certain trust about actualization of the present state. University students are hopeless both about their future and about their profession in general. Hopelessness may affect the life of the people deeply and its influence over the intention of the students about staying in the sector that they are educated about is an issue of concern. The influence of the hopelessness level of students educating in accounting program of the vocational schools over their intention of staying in accounting sector is measured in this study. It is also aimed to determine the hopelessness status of the people. The population of the study is the students educating in Akdeniz University Accounting Program of Social Sciences Vocational High School. This study reveals whether there is a relation between demographic factors and hopelessness or intention of staying in accounting sector. Survey method is used in this study and analyses were conducted using statistical package programme. Hopelessness score of the students is mild. There are significant differences between, gender, willing to choose accountancy profession after graduation, working experience in accounting, choosing accounting program voluntarily and hopelessness level or intention of staying in accounting sector.
\end{abstract}

Keywords : Accounting education, hopelessness level, intention of staying in accounting sector

JEL Codes: M40, M41, M49

\section{MUHASEBE EĞiTiMi ALAN ÖĞRENCILERIN UMUTSUZLUK DÜZEYLERi VE SEKTÖRDE KALMA NIYETLERININ BELIRLENMESINE YÖNELIK BİR ALAN ARAŞTIRMASI}

\section{ÖZET}

Umutsuzluk kavramı, mevcut durumun gerçekleşeceğine kişilerin mutlak güvenlerini kaybetmesi halidir. Genel anlamda bakıldığında üniversite öğrencileri gerek geleceklerine yönelik, gerekse mesleklerine yönelik umutsuzluk yaşamaktadır. Bireylerin hayatını derinden etkileyebilen umutsuzluğun, öğrencilerin eğitimini almakta oldukları sektörde kalma niyetlerini etkileme durumu merak konusudur. Yapılan bu çalışmada meslek yüksekokullarının muhasebe bölümünde öğrenim gören öğrencilerin umutsuzluk düzeylerinin, sektörde kalma niyetlerini etkileme durumu ölçülmüştür. Aynı zamanda bu çalışma ile kişilerin mevcut umutsuzluk durumlarının tespit edilmesi amaçlanmıştır. Çalışmada öğrencilerin çeşitli demografik verileri ile umutsuzluk ve sektörde kalma niyetleri arasında bir ilişki olup olmadığı da ortaya konmuştur. Çalışmanın örneklemini Akdeniz Üniversitesi Sosyal Bilimler Meslek Yüksekokulu'nda muhasebe eğitimi alan öğrenciler oluşturmaktadır. Çalışmada anket yöntemi kullanıımış olup, veriler bir istatistik paket programında analiz edilmiştir. Öğrencilerin umutsuzluk puanı hafif umutsuz düzeyindedir. Cinsiyet, mezun olduktan sonra muhasebecilik mesleğini seçme, muhasebe alanında iş deneyimi ve muhasebe bölümünü isteyerek seçme değişkenleri ile umutsuzluk ve sektörde kalma niyetleri arasında anlamlı farklılıklar bulunmuştur.

AnahtarKelimeler: Muhasebe eğitimi, umutsuzluk düzeyi, muhasebe sektöründe kalma niyeti JEL Kodları: M40, M41, M49

* Corresponding author 


\section{GiRiş}

Günümüzde yaşanan ekonomik sıkıntılar, geleceğe yönelik belirsizlikler, işsizlik oranındaki artış, üniversite sayısındaki artış ve buna bağı olarak artan yükseköğretim mezunu sayısının, gençlerin gelecekle ilgili olumlu beklentiler içine girmelerini engellediği ve moral durumlarını negatif yönde etkilediği söylenebilir. Ayrıca iş hayatındaki belirsizlikler ya da kaygı duymanın, gençlerin sektörde (işte) kalma niyetlerini olumsuz yönde etkilediği ifade edilebilir (Özel, 2014). Nitekim TUik verilerine göre; Türkiye nüfusunun (77 milyon 695 bin 904 kişi) \%16,5'ini "15-24" yaş grubundaki genç nüfus (12 milyon 782 bin 381 kişi) oluşturmaktadır. Türkiye'de 2013-14 öğrenim döneminde yükseköğretim okullaşma oranı bir önceki yıla göre 1,4 puan artış göstererek \%39,9'a yükselmiştir. Yaşam Memnuniyeti Araştırması (YMA) sonuçlarına göre gelecekten umutlu olan genç oranı 2013 yılında \%83,9 iken 2014 yılında \%78 olmuştur. Genç erkekler, 2014 yılında \%79,7 oranında geleceklerinden umutlu iken, genç kadınlarda bu oran \%76,4 olarak gerçekleşmiştir. Gençlerin \%65,1'i, 2013 yılında kendini mutlu hissederken, bu oran 2014 yılında 4 puan düşerek \%61,2 olmuştur. Mutluluk oranı 2014 yılında genç erkeklerde \%60 genç kadınlarda ise \%62,4 olarak gerçekleşmiştir. (İstatistiklerle Gençlik, 2014, 2016).

İstatistiksel olarak da veriler incelendiğinde gelecekten umutlu olan gençlerin sayısında yıllar itibariyle azalma olduğu dikkat çekmektedir. Türk Dil Kurumu Güncel Türkçe Sözlükte umut, " ummaktan doğan duygu; olması beklenilen veya olacağı düşünülen şey" olarak tanımlanmaktadır (Güncel Türkçe Sözlük, 2016). Ummak ise, "bir şeyin olmasını beklemek; sanmak, tahmin etmek olarak tanımlanmaktadır (Güncel Türkçe Sözlük, 2016). Buna göre umut, bireyin gelecekte olmasını istediği şey veya olaylar için olumlu duygulara sahip olması ve beklentilerinin gerçekleşeceğine güven duyması halidir. Umut kavramının karşıtı umutsuzluk kavramıdır. Umutta amaca ulaşmak için uygulamaya konulan planların başarılacağı beklentisi varken; umutsuzlukta başarısızlık yargısı vardır. Umut ve umutsuzluk, bireyin gelecekteki amaçlarına ulaşma olanaklarının olası yansımalarıdır (Dilbaz ve Seber, 1993).

1974 yılında Beck ve arkadaşları psikoterapi gören bir grup hastayı gözlemleyerek umutsuzluğu belirleyen "Beck Umutsuzluk Ölçeği”ni geliştirmişlerdir. Bireyin geleceğe yönelik karamsarlık düzeyini belirlemeyi amaçlayan ölçek 20 önermeden oluşmuştur. Ölçek, gelecek ile ilgili duygular, motivasyon kaybı ve gelecek ile ilgili beklentiler olmak üzere üç faktörden oluşmaktadır (Beck ve diğ., 1974). Ölçek geçerlik ve güvenilirliğinin yüksek olduğunu ortaya koyan çalışmalar yapılmış olup bireyin negatif beklentilerini yansıtmaktadır (Seber ve diğ., 1993; Durak ve Palabıyıkoğlu, 1994).

Bu çalışmanın amacı, Meslek Yüksekokullarının Muhasebe bölümünde öğrenim gören öğrencilerin "Beck Umutsuzluk Ölçeği” ne göre umutsuzluk düzeylerini belirlemek, çeşitli demografik verileri ile umutsuzluk ve sektörde kalma niyetleri arasında bir farklılık olup olmadığını ve umutsuzluk düzeyleri ile sektörde kalma niyetleri arasında bir ilişki olup olmadığını ortaya koymaktır.

\section{LITERATÜR TARAMASI}

Deveci ve diğ. (2011) mesleki eğitim merkezi öğrencilerinin umutsuzluk düzeyinin belirlenmesi ve etkileyen faktörlerin tanımlanması için yaptıkları çalışmada, umutsuzluk düzeyini; erkeklerde, haftada beş günden fazla çalışanlarda, iş değişikliği yapmış olanlarda, günlük çalışma süresi sekiz saatten fazla olanlarda, yaptığı işi sevmeyenlerde, kronik bir hastalığı olduğunu ifade edenlerde, sigara ve alkol kullananlarda daha yüksek bulmuşlardır.

Şahin (2009) eğitim fakültesinde öğrenim gören öğrencilerin umutsuzluk düzeylerini belirlemek ve öğrencilerin umutsuzluk düzeylerinin sınıf düzeyine, cinsiyete, anabilim dallarına, kaldıkları yerlere, algılanan gelir düzeyine, babanın ve annenin eğitim düzeyine göre değişip değişmediğini incelemeyi amaçlamıştır. Araştırmanın bulguları, öğrencilerin umutsuzluk düzeylerinin düşük olmasıyla birlikte, bazı öğrencilerin yoğun umutsuzluk yaşadıklarını, cinsiyete (erkek öğrencilerin umutsuzluk düzeyi kızlardan daha fazladır), öğrenim gördükleri anabilim dallarına, kaldıkları yerlere ve algılanan gelir düzeyine göre öğrencilerin umutsuzluk düzeyleri arasında anlamlı farklılıklar olduğunu göstermektedir. Ayrıca çalışmada sınıf düzeyine, babanın ve annenin eğitim düzeyine göre anlamlı fark olmadığı saptanmıştır. 
Doğan (2012) resim öğretmeni adaylarının umutsuzluk düzeyini, cinsiyet değişkeni ve sınıf düzeyi açısından adayların umutsuzluk düzeylerinde anlamlı bir farklılık olup olmadığıı araştırmış ve öğretmen adaylarının umutsuzluk düzeylerinin düşük olduğu sonucuna ulaşmıştır. Bunun yanı sıra cinsiyet değişkeni ve sınıf düzeyleri bakımından öğretmen adaylarının umutsuzluk düzeyleri arasında anlamlı bir farklılık bulunmamıştır.

Aydın ve diğ. (2013) Sağlık yüksekokulu ve sağlık meslek lisesi öğrencilerinin umutsuzluk düzeylerini ölçmüş, öğrencilerin \% 35.6'sının iş bulma endişesi yaşadığını, en fazla iş endişesi yaşayan bölümün diş protez teknikerliği olduğunu saptamışlardır. Öğrencilerin cinsiyet, öğrenim gördüğü okul ve bölüm ile umutsuzluk puanları arasında anlamlı ilişki olmadığı iş bulma endişesi ve akademik başarı durumu ile anlamlı ilişki olduğu saptanmıştır. Öğrencilerin çoğunluğunun iş bulma endişesi yaşamadığı, yaşayan öğrencilerin daha umutsuz olduğu, umutsuzlukları üzerinde başarı durumlarının etkili olduğunu belirlemişlerdir.

Üngören ve Ehtiyar (2009) Türk ve Alman öğrencilerin umutsuzluk düzeylerinin karşılaştırılması ve umutsuzluk düzeylerini etkileyen faktörlerin belirlenmesi amacıyla yaptıkları çalışmanın sonucunda Türk öğrencilerin umutsuzluk düzeylerinin yordayıcıları olarak eğitim memnuniyeti, okuldaki başarı durumu, gelir durumu, cinsiyet (kız öğrencilerin umutsuzluk düzeyleri, erkek öğrencilerden daha yüksektir), arkadaş ilişkiler düzeyinin olduğu saptanmıştır. Alman öğrencilerin ise sadece "eğitim memnuniyeti" değişkeninin öğrencilerin umutsuzluk düzeyleri üzerinde düşük düzeyde de olsa yordayıcı olduğu görülmüştür. Elde edilen sonuçlara göre, Türk ve Alman öğrencilerin umutsuzluk düzeylerini etkileyen ortak değişkenin eğitim memnuniyeti olduğu saptanmıştır.

Dursun ve Aytaç (2012)'ın üniversite son sınıfta eğitim gören öğrencilerin, kaygı ve umutsuzluk düzeylerini ortaya çıkarmak, ayrıca öğrencilerin işgücü piyasasına yönelik beklenti ve iş deneyimi ile durumluk-sürekli kaygı ve umutsuzluk düzeyleri arasındaki ilişkiyi tespit etmek amacıyla yaptıkları çalışmada, iş bulma ümidi, iş önceliği ile umutsuzluk ve durumluk ve sürekli kaygı düzeyleri arasında; diğer taraftan iş deneyimi ile umutsuzluk ve sürekli kaygı düzeyleri arasında anlamlı bir farklılık tespit edilmiştir. Ayrıca, cinsiyet açısından öğrencilerin kaygı ve umutsuzluk düzeyleri arasında anlamlı farklılıklar bulunmuş olup kız öğrencilerin umutsuzluk düzeyleri, erkek öğrencilerden daha yüksektir.

Aktağ ve Alpay (2015), Abant İzzet Baysal Üniversitesi, Beden Eğitimi ve Spor Yüksekokulunda, Beden Eğitimi Öğretmenliği, Antrenörlük Eğitimi ve Spor Yöneticiliği Bölümlerinde okuyan öğrencilerin umutsuzluk düzeylerini cinsiyet, sınıf ve bölümlere göre incelemişlerdir. Elde edilen sonuçlara göre öğrencilerin umutsuzluk düzeyleri cinsiyet değişkenine göre incelendiğinde kız ve erkek öğrencilerin umutsuzluk düzeyleri arasında anlamlı bir farklıık bulunmuştur. Erkek öğrencilerin umutsuzluk düzeyleri kız öğrencilere göre daha fazladır. Öğrencilerin umutsuzluk düzeyleri hem bölümlerine hem de sınıflarına göre anlamlı bir farklılık göstermemiştir.

Üstün ve diğ. (2014)'ninüniversite son sınıf öğrencilerinin iş bulmaya ilişkin umutsuzluk düzeylerinin bazı değişkenler açısından incelenmesi amacıyla yaptıkları çalışmada öğrencilerin iş bulmaya ilişkin umutsuzluk düzeylerinin, öğrenim gördükleri fakülte ve yüksekokullara göre farklılaştığı ortaya çıkmış, iş bulma süresinin 6 aydan kısa olacağını ifade eden öğrencilerin toplam umutsuzluk puanlarının anlamlı derecede düşük olduğu görülmüştür. Ayrıca okudukları bölümü isteyerek seçmeyenlerin umutsuzluk puanları, isteyerek seçenlere göre anlamlı derecede daha yüksektir.

Dereli ve Kabataş (2009) Muğla Sağlık Yüksekokulu son sınıf öğrencilerinin iş bulma endişeleri ve umutsuzluk düzeylerini belirlemek amacıyla yaptıkları çalışmada öğrencilerin; yaş grubu, cinsiyet, doğum yeri, medeni, gelir, mesleklerini seçme durumu, okudukları bölüm, iş bulmada kullanacakları yöntem durumu ile umutsuzluk puanları arasında anlamlı ilişki olmadığı iş bulmaya yönelik endişe ve mezun olduktan sonra iş bulabileceklerini düşündükleri süreye göre anlamlı ilişki olduğu tespit edilmiştir. İş bulma konusunda endişeli olan öğrencilerin, endişeli olmayanlara göre daha umutsuz, kısa sürede iş bulabileceğini düşünenlerinde diğer gruplara göre daha umutsuz olduğu tespit edilmiştir.

\section{VERI VE YÖNTEM}

Araştırmanın evreni Akdeniz Üniversitesi Sosyal Bilimler Meslek Yüksekokulu'nda Muhasebe ve Vergi Uygulamaları programında eğitim gören önlisans öğrencileridir. Yapılan anket çalışmasında programa kayıtlı yaklaşık 1000 öğrenciden toplam 338 öğrenciye ulaşılmıştır. 6 anket analize uygun görülmemiş ve toplam 332 anket uygulamaya alınmıştır. Veri toplama aracı olarak, çalışmanın yazarlarının oluşturduğu demografik sorular, 
20 maddeden oluşan, kendini değerlendirme türü bir ölçek olan Beck ve arkadaşlarının (1974) geliştirdiği Beck umutsuzluk ölçeği ve Özel'in (2014) çalışmasından alınan ve 4 maddeden oluşan Sektörde Kalma Niyeti Ölçeği kullanılmıştır. Özel'in (2014: 267) çalışmasındaki ölçekler uluslar arası düzeyde kullanılan ölçekler olup tercümeleri araştırmacı ve İngiliz dili uzmanları tarafından gerçekleştirilmiştir ve bu çalışmada kullanılan Sektörde Kalma Niyeti Ölçeği'nde değerlendirme ölçütü olarak "1. Hiç Katılmıyorum” ile "5.Tamamen Katılıyorum" arasında değişen 5'li Likert ölçeği kullanılmıştır.

Beck Umutsuzluk Ölçeğinde bireylerden onlara uygun olan "evet", uygun olmayanlar ifadeler için "hayır" seçeneklerini seçmesi istenmektedir. 1, 3, 5, 6, 8, 10, 13, 15, 19. sorularda "hayır"; 2, 4, 7, 9, 11, 12, 14, 16, 17, 18, 20. sorulara ise "evet" yanıtı için 1 puan verilir. Minimum puan 0, maksimum puan 20' dir. Alınan puanlar yüksek olduğunda bireydeki umutsuzluğun yüksek olduğu varsayılır. Elde edilen toplam puan umutsuzluk puanı olarak kabul edilmektedir. Ölçekten elde edilen puanlar dört grup içinde sınıflandırılmıştır. Buna göre 0-3: umutsuz olmama hali, 4-8: hafif umutsuzluk var, 9-14: orta seviyede umutsuzluk, 15-20: ileri derecede umutsuzluk var olarak belirlenmiştir. Fakat ölçeğin kesme puanıyla ilgili 9 ve üzerinde olan umutsuzluk puanının intiharı yordama konusunda kullanılabileceği bildirilmektedir (Beck ve Steer (1988) -aktaran Aktağ ve Alpay, 2015: 18-; Derebaşı, 1996: 35; Kızılgeçit, 2011: 124). Beck ve arkadaşları ölçekte 3 faktör bulmuşlardır. 1, 6, 13, 15, 19. maddeler gelecek ile ilgili duygular faktörünü; 2, 3, 9, 11, 12, 16, 17, 20. maddeler motivasyon kaybı faktörünü; 4, 7, 8, 14, 18. maddeler gelecek ile ilgili beklentiler faktörünü oluşturmaktadır (Beck ve diğ. 1974: 864; Derebaşı, 1996: 35; Durak ve Palabıyıkoğlu, 1994: 318). Beck Umutsuzluk Ölçeği'nin güvenilirlik ve geçerlilik çalışmaları Türkiye'de Seber ve ark. (1993), Durak ve Palabıyıkoğlu (1994) ve Derebaşı (1996) tarafından yapılmıştır.

\section{BULGULAR VE TARTIŞMA}

Toplanan veriler, araştırmanın amacına uygun olarak 4 aşamada değerlendirilmiştir: Öğrencilerin umutsuzluk düzeyi puanı belirlenmiş, umutsuzluk düzeylerinin ve sektörde kalma niyetlerinin çeşitli demografik verilere göre farklılaşıp farklılaşmadığını anlamak için Mann Whitney $U$ testi uygulanmış, umutsuzluk düzeyleri ile sektörde kalma niyetleri arasında bir ilişki olup olmadığını anlamak için de Korelasyon testi uygulanmıştır. Analizlerde anlamlı çıkan sonuçlar tablolarda gösterilmiştir.

Tablo 1:Araştırmaya Katılan Öğrencilerinin Umutsuzluk Ölçeği Puan Ortalaması

\begin{tabular}{lcc}
\hline $\mathbf{X} \pm$ SS & En Düşük Puan & En Yüksek Puan \\
\hline $6,54 \pm 4,08$ & 0 & 19 \\
\hline
\end{tabular}

Tablo 1'de görüldüğü gibi, öğrencilerin umutsuzluk düzeyi ortalaması 6,54 ve standart sapması 4,08'dir Ölçekten elde edilen en düşük puan 0 ve en yüksek puan 19 olup, dağılımın genişliği 19'dur. Umutsuzluk ölçeği puanlarının yorumlanmasında dikkate alınabilecek puan aralıkları dikkate alındığında, öğrencilerin umutsuzluk düzeylerine ilişkin bu ortalamanın, hafif umutsuzluk (4-8 puan aralığı) düzeyinde olduğu anlaşılmaktadır. Aktağ ve Alpay (2015), Deveci ve diğ. (2011), Şahin (2009), Doğan (2012), Üngören ve Ehtiyar (2009) ile Dursun ve Aytaç (2012)'ın çalışmalarında da umutsuzluk düzeyleri "hafif umutsuz"dur.

Tablo 2: Öğrencilerin Demografik Özellikleri Bakımından Umutsuzluk Düzeyleri Arasındaki Farklılıklara İlişkin Mann Whitney U Testi Sonuçları

\begin{tabular}{lcccc}
\hline & $\mathbf{N}$ & $\mathbf{X} \pm$ SS & $\mathbf{Z}$ & $\mathbf{P}$ \\
\hline Cinsiyet & & & & \\
Kız & 177 & $5,96 \pm 3,87$ & $-2,758$ & 0,006 \\
Erkek & 155 & $7,19 \pm 4,23$ & &
\end{tabular}


Mezun olduktan sonra muhasebecilik mesleğini seçme

$\begin{array}{lllll}\text { Evet } & 236 & 6,13 \pm 4,00 & -2,899 & 0,004 \\ \text { Hayır } & 96 & 7,54 \pm 4,25 & & \end{array}$

Muhasebe alanında iş deneyimi

$\begin{array}{lllll}\text { Evet } & 161 & 6,12 \pm 4,02 & -2,009 & 0,045 \\ \text { Hayır } & 170 & 6,92 \pm 4,13 & & \end{array}$

Muhasebe bölümünü isteyerek seçme

\begin{tabular}{lllll} 
Evet & 192 & $5,89 \pm 3,74$ & $-3,249$ & 0,001 \\
Hayır & 140 & $7,43 \pm 4,37$ & & \\
\hline
\end{tabular}

Tablo 2'ye göre öğrencilerin cinsiyet, mezun olduktan sonra muhasebecilik mesleğini seçmeyi düşünme, muhasebe alanında iş deneyimi olması ve muhasebe bölümünü isteyerek seçmeleriyle umutsuzluk düzeyleri arasında anlamlı farklılıklar vardır. Kızların erkeklere göre, mezun olduktan sonra muhasebecilik mesleğini seçmeyi düşünenlerin düşünmeyenlere göre, muhasebe alanında iş deneyimi olanların olmayanlara göre ve muhasebe bölümünü isteyerek seçenlerin seçmeyenlere göre umutsuzluk düzeyi daha düşüktür. Aktağ ve Alpay (2015), Deveci ve diğ. (2011) ve Şahin (2009)'in çalışmalarında da erkeklerin umutsuzluk düzeyleri kızlardan daha fazla bulunmuştur. Üstün ve diğ. (2014)'nin çalışmasında da okudukları bölümleri isteyerek seçenlerin umutsuzluk puanları daha düşüktür.

Tablo 3: Öğrencilerin Demografik Özellikleri ile Sektörde Kalma Niyetleri arasındaki farklılıklara ilişkin Mann Whitney U Testi Sonuçları

\begin{tabular}{|c|c|c|}
\hline $\mathbf{N}$ & $x$ & 7 \\
\hline
\end{tabular}

SKN 1: Çalıșılan sektörde uzun süre çalıșmayı planlama ile

Mezun olduktan sonra muhasebecilik mesleğini seçme

$\begin{array}{lllll}\text { Evet } & 236 & 4,00 & -8,819 & 0,000 \\ \text { Hayır } & 96 & 2,43 & & \end{array}$

Muhasebe alanında iş deneyimi

$\begin{array}{lllll}\text { Evet } & 161 & 3,83 & -3,576 & 0,000 \\ \text { Hayır } & 170 & 3,27 & & \end{array}$

Muhasebe bölümünü isteyerek seçme

$\begin{array}{lllll}\text { Evet } & 192 & 3,97 & -6,546 & 0,000 \\ \text { Hayır } & 140 & 2,96 & & \end{array}$


SKN 2: Çalışılan sektörde en azından 10 yıl daha çalışmayı planlama ile

Mezun olduktan sonra muhasebecilik mesleğini seçme

$\begin{array}{lllll}\text { Evet } & 236 & 3,72 & -7,244 & 0,000 \\ \text { Hayır } & 96 & 2,46 & & \end{array}$

Muhasebe alanında iş deneyimi

$\begin{array}{lllll}\text { Evet } & 161 & 3,66 & -3,894 & 0,000 \\ \text { Hayır } & 170 & 3,07 & & \end{array}$

Muhasebe bölümünü isteyerek seçme

$\begin{array}{lllll}\text { Evet } & 192 & 3,71 & -5,503 & 0,000 \\ \text { Hayır } & 140 & 2,87 & & \end{array}$

SKN 3: Mevcut koșullar değișmediği sürece bu sektörde kalmayı planlama ile

Mezun olduktan sonra muhasebecilik mesleğini seçme

$\begin{array}{lllll}\text { Evet } & 236 & 3,85 & -8,909 & 0,000 \\ \text { Hayır } & 96 & 2,33 & & \end{array}$

Muhasebe alanında iş deneyimi

$\begin{array}{lllll}\text { Evet } & 161 & 3,72 & -3,917 & 0,000 \\ \text { Hayır } & 170 & 3,12 & & \end{array}$

Muhasebe bölümünü isteyerek seçme

$\begin{array}{lllll}\text { Evet } & 192 & 3,80 & -6,290 & 0,000 \\ \text { Hayır } & 140 & 2,88 & & \end{array}$

SKN 4: Bu sektörde iş hayatının sonuna kadar çalıșmayı planlama ile

Mezun olduktan sonra muhasebecilik mesleğini seçme

$\begin{array}{lllll}\text { Evet } & 236 & 3,50 & -8,155 & 0,000 \\ \text { Hayır } & 96 & 2,12 & & \end{array}$

Muhasebe alanında iş deneyimi

$\begin{array}{lllll}\text { Evet } & 161 & 3,34 & -3,076 & 0,002 \\ \text { Hayır } & 170 & 2,87 & & \end{array}$




\section{Muhasebe bölümünü isteyerek seçme}

$\begin{array}{lllll}\text { Evet } & 192 & 3,45 & -5,496 & 0,000 \\ \text { Hayır } & 140 & 2,61 & & \end{array}$

Tablo 3'e göre öğrencilerin mezun olduktan sonra muhasebecilik mesleğini seçmeyi düşünme, muhasebe alanında iş deneyimi olması ve muhasebe bölümünü isteyerek seçmeleriyle Sektörde Kalma Niyetleri arasında anlamlı farklılıklar vardır. Mezun olduktan sonra muhasebecilik mesleğini seçmeyi düşünenlerin düşünmeyenlere göre, muhasebe alanında iş deneyimi olanların olmayanlara göre ve muhasebe bölümünü isteyerek seçenlerin seçmeyenlere göre "çalışılan sektörde uzun süre çalışmayı planlama", "çalışılan sektörde en azından 10 yıl daha çalışmayı planlama", "mevcut koşullar değişmediği sürece bu sektörde kalmayı planlama", "sektörde iş hayatının sonuna kadar çalışmayı planlama" ifadelerinden oluşan Sektörde Kalma Niyetleri daha yüksektir.

Tablo 4. Öğrencilerin Umutsuzluk Düzeyleri ile Sektörde Kalma Niyetleri arasında Korelasyon Analizi

\begin{tabular}{|c|c|c|c|}
\hline Değişken & $\mathbf{N}$ & Spearman'sRho & $\mathrm{P}$ \\
\hline SKN 1: Çalışılan sektörde uzun süre çalışmayı planlama & 332 &,- 174 & 0,001 \\
\hline \multicolumn{4}{|l|}{ Umutsuzluk düzeyi } \\
\hline SKN 2: Çalışılan sektörde en az 10 yıl daha çalışmayı planlama & 332 &,- 159 & 0,004 \\
\hline \multicolumn{4}{|l|}{ Umutsuzluk düzeyi } \\
\hline SKN 3: Mevcut koşullar değişmediği sürece bu sektörde kalmayı planlama & 332 &,- 160 & 0,004 \\
\hline \multicolumn{4}{|l|}{ Umutsuzluk düzeyi } \\
\hline SKN 4: Bu sektörde iş hayatının sonuna kadar çalışmayı planlama & 332 &,- 138 & 0,012 \\
\hline
\end{tabular}

Tablo 4’te görüleceği gibi, öğrencilerin Sektörde Kalma Niyetleri ve Umutsuzluk düzeyleri arasındaki ilişkiye yönelik Korelasyon analizine göre değişkenler arasında negatif yönlü nispeten çok zayıf bir ilişki vardır (11-20 arası nispeten çok zayıf -Nakip, 2003:322-11-20) ve sonuçlar anlamlıdır. Umutsuzluk düzeyi arttıkça sektörde kalma niyeti çok az miktarda azalmaktadır.

\section{SONUÇ}

Bu çalışmanın amacı, öğrencilerin umutsuzluk düzeylerini belirlemek, çeşitli demografik verileri ile umutsuzluk ve sektörde kalma niyetleri arasında bir farklılık olup olmadığını ve umutsuzluk düzeyleri ile sektörde kalma niyetleri arasında bir ilişki olup olmadığını ortaya koymaktır. Umutsuzluk düzeyi, geçerlilik ve güvenilirliği test edilip birçok çalışmada kullanılmış olan "Beck Umutsuzluk Ölçeği” ile ölçülmüştür.

Öğrencilerin umutsuzluk düzeyleri, çeşitli demografik verilere göre farklılaşmaktadır. Kızların, mezun olduktan sonra muhasebecilik mesleğini seçmeyi düşünenlerin, muhasebe alanında iş deneyimi olanların ve muhasebe bölümünü isteyerek seçenlerin umutsuzluk düzeyi daha düşüktür. 
Öğrencilerin sektörde kalma niyetleri de, çeşitli demografik verilere göre farklılaşmaktadır. Mezun olduktan sonra muhasebecilik mesleğini seçmeyi düşünenlerin, muhasebe alanında iş deneyimi olanların ve muhasebe bölümünü isteyerek seçenlerin sektörde kalma niyetleri daha yüksektir.

Sektörde Kalma Niyetleri ile Umutsuzluk düzeyleri arasındaki ilişki de negatif yönlü ve nispeten çok zayıf olduğundan umutsuzluk düzeyi arttıkça sektörde kalma niyetinin çok az miktarda azaldığı anlaşılmaktadır.

Mezun olduktan sonra muhasebecilik mesleğini seçmeyi düşünen, bu konuda iş deneyimi olan ve okuduğu bölümü isteyerek seçmiş olanların hem umutsuzluk puanlarının daha düşük, hem de sektörde kalma niyetlerinin daha yüksek olması, gençlerin en büyük kaygılarından biri olan işsizlik konusunu çözmek için bir yola girip seçim yapmakta olduklarını düşündürmektedir.

Öğrencilerin umutsuzluk puanları ortalaması "hafif umutsuz" düzeyde bulunmuştur, ancak öğrencilerin $\% 23,7^{\prime}$ sinin umutsuzluk puanı 9 ve üzerinde olup orta düzeyde umutsuz, $\% 4,8^{\prime}$ inin ise umutsuzluk puanı 15 ve üzerinde olup ileri düzeyde umutsuzdur. Bu da gençlerin bir bölümünün gelecekle ilgili oldukça kaygılı olduğunu düşündürebilir. Öğrencilerin umutsuzluk düzeylerini azaltmak için umutsuzluğu etkileyen faktörler araştırııp rehberlik faaliyetleri artırılmalı, iş olanaklarını artırmak için sektörle işbirliği halinde olunmalıdır. Ayrıca iyi bir iş bulup o işte kalıcı olmanın, aldıkları eğitimin yanında kendilerini geliştirmekten geçtiği konusunda öğrencilerde farkındalık yaratılmalı, gerekli donanımı elde etme konusunda yol gösterilmelidir.

Bu çalışmanın sınırlııklarından biri, belli bir meslek yüksekokulunun belli bir programındaki öğrencilere uygulanmış olmasıdır. Farklı programlardaki ve okullardaki öğrencilere böyle bir çalışmanın uygulanıp umutsuzluk düzeyini ve sektörde kalma niyetini etkileyen başka faktörlerin de ele alınması önerilir.

\section{KAYNAKLAR}

Aktağ, I. \& Alpay, D. D. 2015, “Abant İzzet Baysal Üniversitesi Beden Eğitimi ve Spor Yüksekokulunda öğrenim gören öğrencilerinin umutsuzluk düzeyleri”, Abant Izzet BaysalÜniversitesi Eğitim Fakültesi Dergisi, vol. 15, no. 1, pp. 15-24.

Aydın, M., Erdoğan, S., Yurdakul, M. \& Eker, A. 2013, "Sağlık yüksekokulu ve sağlık meslek lisesi öğrencilerinin umutsuzluk düzeyleri”, S.D.Ü Sağlık Bilimleri Dergisi, vol. 4. no. 1, pp. 1-6.

Beck, A. T., Weissman, A., Lester, D. \&Trexler, L. 1974, "The measurement of pessimism: The Hopelessness Scale”, Journal of Consulting and Clinical Psychology, vol. 12, no. 6, pp. 861-865.

Derebaşı, I. 1996, “Beck Umutsuzluk Ölçeğinin Ege Üniversitesi Öğrencileri Üzerinde Geliştirilmesi”, (Yayınlanmamış Yüksek Lisans Tezi), Ege Üniversitesi Sosyal Bilimler Enstitüsü, İzmir.

Dereli, F. \& Kabataş, S. 2009, "Sağlık Yüksekokulu Son sınıf Öğrencilerinin İş Bulma Endişeleri ve Umutsuzluk Düzeylerinin Belirlenmesi”, Yeni Tıp Dergisi, vol. 26, pp. 31-36.

Deveci, S.E.,Ulutaşdemir, N. \& Açık, Y. 2011, "Bir mesleki eğitim merkezi öğrencilerinde umutsuzluk düzeyi ve etkileyen faktörler", Dicle Tıp Dergisi, vol. 38, no. 3, pp. 321-317.

Dilbaz, N., \& Seber, G. 1993, “Umutsuzluk Kavramı: Depresyon ve İntiharda Önemi”, Kriz, vol. 1, no. 3, pp. $134-138$.

Doğan, P. 2012, “Resim Öğretmeni Adaylarının Umutsuzluk Düzeylerinin İncelenmesi”, M.Ü. Atatürk Eğitim Fakültesi Eğitim Bilimleri Dergisi, vol. 36, pp. 115-127.

Durak, A. \& Palabıyıkoğlu, R. 1994, “Beck Umutsuzluk Ölçeği geçerlilik çalışması”, Kriz Dergisi, vol.2, no. 2, pp. 311-319.

Dursun, S. \& Aytaç, S. 2012, “Üniversite Öğrencilerinin İşgücü Piyasasına Yönelik Beklentileri Ve İş Deneyimleri İle Umutsuzluk ve Kaygı Düzeyleri Arasındaki iliş̧ki Üzerine Bir Araştırma”, CBÜ Sosyal Bilimler Dergisi, vol. 10, no. 1, pp. 373-388.

Güncel Türkçe Sözlük. (2016, Mart 27). www.tdk.gov.tr:

http://www.tdk.gov.tr/index.php?option=com_gts\&arama=gts\&guid=TDK.GTS.56f822dc443907.25039767 adresinden alınmıştır.

Güncel Türkçe Sözlük. (2016, Mart 27). www.tdk.gov.tr:

http://www.tdk.gov.tr/index.php?option=com_gts\&arama=gts\&guid=TDK.GTS.56f821d53ff181.44895226 adresinden alınmıştır.

Istatistiklerle Gençlik, 2014. (2016, MArt 27). www.tuik.gov.tr: http://www.tuik.gov.tr/PreHaberBultenleri.do?id=18625 adresinden alınmıştır.

Nakip, M. 2003, Pazarlama Araştırmaları Teknikler ve SPSS Destekli Uygulamaları, Seçkin Kitabevi, Ankara 
Özel, N. 2014, "iş̧ Tatmini İ̧̧ Güvencesi Ve Örgütsel Özdeşlik Algılarının Çalışanların Işte Kalma Niyetleri Üzerindeki Etkisi: Bolu Imalat Sektör Çalışanları Üzerinde Bir Araştırma", Yönetim ve Ekonomi Araştırmaları Dergisi, vol. 24, pp. 262-280.

Seber, G., Dilbaz, N., Kaptanoğlu, C. \& Tekin, D. 1993, “Umutsuzluk ölçeği: Geçerlilik ve güvenirliği”, Kriz Dergisi, vol. 1, 139-142.

Şahin, C. 2009, "Eğitim Fakültesinde Öğrenim Gören Öğrencilerin Umutsuzluk Düzeyleri”, Selçuk Üniversitesi Ahmet Keleşoğlu Eğitim Fakültesi Dergisi, vol. 27, pp. 271-286.

Üngören, E. \&Ehtiyar, R. 2009, “Türk Ve Alman Öğrencilerin Umutsuzluk Düzeylerinin Karşılaştırılması Ve Umutsuzluk Düzeylerini Etkileyen Faktörlerin Belirlenmesi: Turizm Eğitimi Alan Öğrenciler Üzerinde Bir Araştırma”, Journal of Yaşar University, vol. 4, no. 14, pp. 2093-2127.

Üstün, G.,Dedekoç, Ş., Kavalalı, T., Öztürk, F., Sapçı, Y. \& Can, S. 2014, “Üniversite Son Sınıf Öğrencilerinin iş̧ Bulmaya ilişsin Umutsuzluk Düzeylerinin İncelenmesi”, Amasya Üniversitesi Eğitim Fakültesi Dergisi , vol. 3, no. 2, $200-221$.

Yükseköğretim Bilgi Yönetim Sistemi. (2016, Mart 27). https://istatistik.yok.gov.tr/. adresinden alınmıştır 